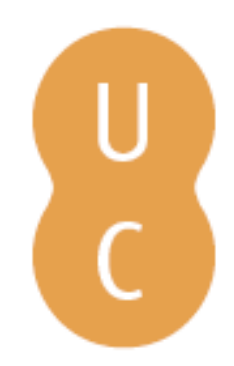

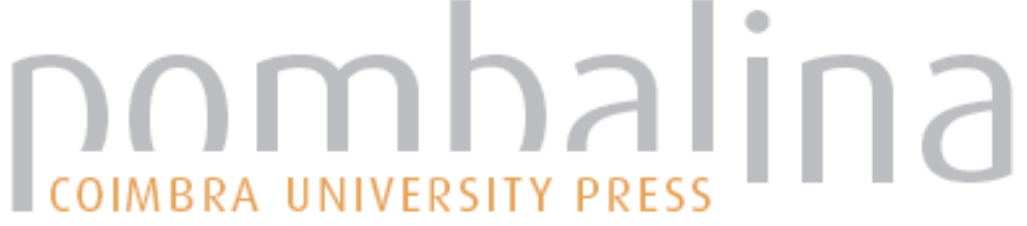

\section{Arte e poética da memória nas redondilhas}

\author{
Autor(es): $\quad$ Peloso, Silvano
}

Publicado por: Imprensa da Universidade de Coimbra

URL

persistente: URI:http://hdl.handle.net/10316.2/30778

DOI: $\quad$ DOI:http://dx.doi.org/10.14195/978-989-26-0569-2_14

Accessed : $\quad$ 26-Apr-2023 12:38:57

A navegação consulta e descarregamento dos títulos inseridos nas Bibliotecas Digitais UC Digitalis, UC Pombalina e UC Impactum, pressupõem a aceitação plena e sem reservas dos Termos e Condições de Uso destas Bibliotecas Digitais, disponíveis em https://digitalis.uc.pt/pt-pt/termos.

Conforme exposto nos referidos Termos e Condições de Uso, o descarregamento de títulos de acesso restrito requer uma licença válida de autorização devendo o utilizador aceder ao(s) documento(s) a partir de um endereço de IP da instituição detentora da supramencionada licença.

Ao utilizador é apenas permitido o descarregamento para uso pessoal, pelo que o emprego do(s) título(s) descarregado(s) para outro fim, designadamente comercial, carece de autorização do respetivo autor ou editor da obra.

Na medida em que todas as obras da UC Digitalis se encontram protegidas pelo Código do Direito de Autor e Direitos Conexos e demais legislação aplicável, toda a cópia, parcial ou total, deste documento, nos casos em que é legalmente admitida, deverá conter ou fazer-se acompanhar por este aviso.

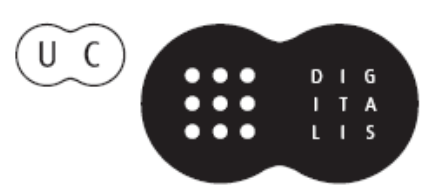




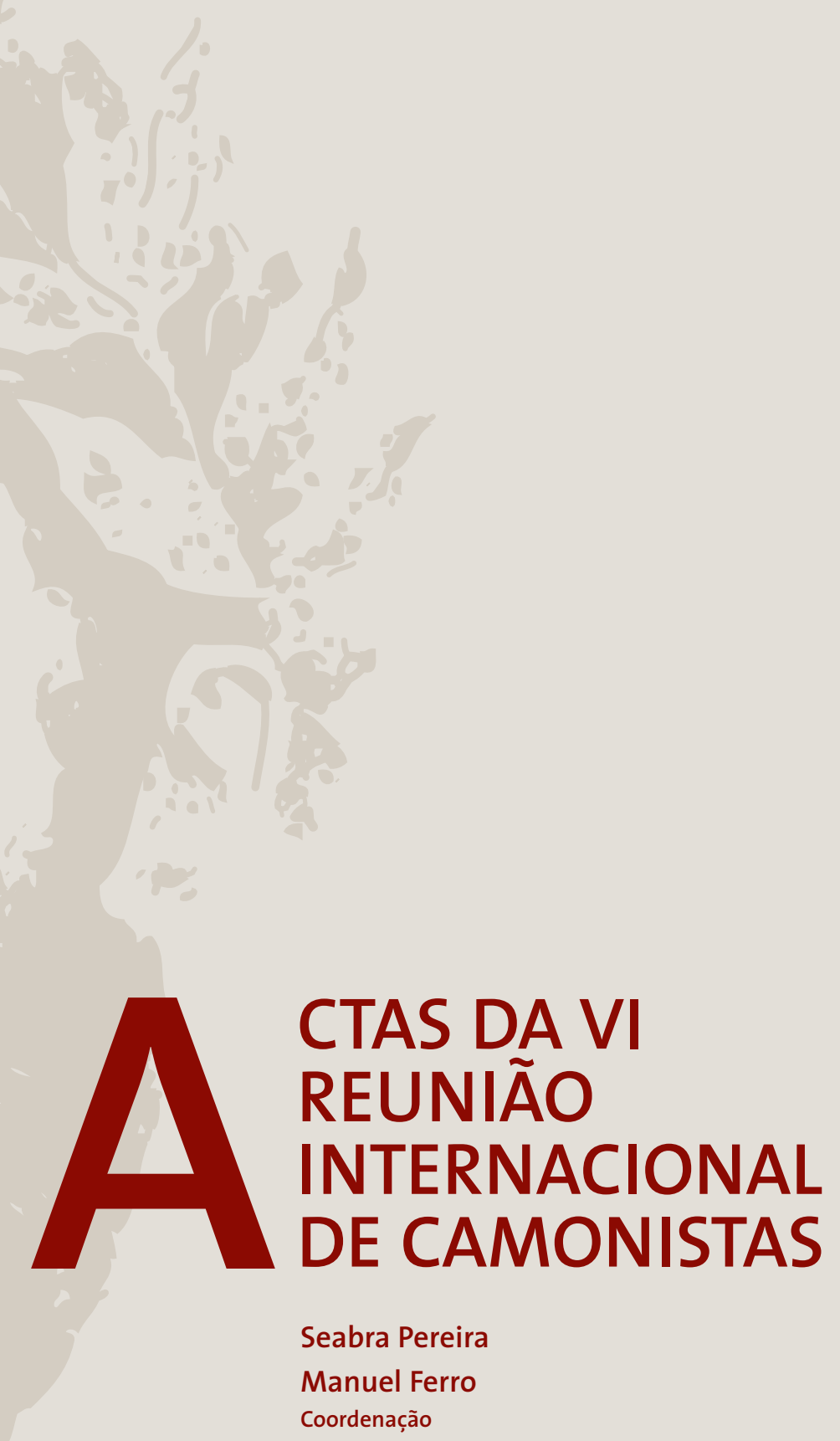




\author{
Silvano Peloso \\ Universidade de Roma "La Sapienza»
}

\title{
ARTE E POÉTICA DA MEMÓRIA NAS REDONDILHAS
}

1 - A obra de Luís de Camóes em geral, mas principalmente o corpus das Líricas, e nele o conjunto das Redondilhas, manifesta claramente a influência de um código cultural fundado sobre uma espécie de ciência das imagens, que reúne e harmoniza diversas formas expressivas e exalta fortemente a função da memória. A memória, em outras palavras, torna-se componente essencial daquele cânone classicista e tradicional que no próprio século XVI se define com exactidão, influenciando durante séculos a reflexão sobre a literatura: da natureza dialógica e intertextual das obras às relaçóes entre escrita, tradição e recepção, tendo sempre como fundamento a estreita correspondência entre palavras e imagens que a memória contribui a criar.

Se, com efeito, a produção do novo passa através da imitação do antigo, a individualidade do escritor se manifestará muitas vezes através da apropriaçáo de um discurso "outro» e escrever significará sobretudo recordar, numa perspectiva fundamentalmente baseada numa relação entre tradição e invenção, em que o papel da memória consiste em dar forma nova às imagens que ela conserva. Ao mesmo tempo a imitação dos modelos aparece como uma competição, um jogo virtuosístico de variaçóes que se exercita sobre palavras e imagens herdadas do passado e seleccionadas pelo código literário. Os esquemas visivos se tornam cada vez mais máquinas para produzir textos em que o modelo retórico fornece o material já pronto para a inventio, oferecendo palavras e imagens predispostas a serem colocadas nos loci do texto. Tudo isto num quadro histórico e cultural onde o advento da imprensa contribui a dilatar aquela relação reflexa entre mente e escrita, entre loci interiores e loci do texto, entre interioridade e exterioridade em que a tradição aristótelica da imaginação (sobretudo o De memoria et reminiscentia, mas também o De sensu et sensibilibus) converge com a tradição neoplatónica e hermética do pneuma, do spiritus phantasticus: isto é, tudo aquilo que no homem torna possível a criação das imagens, dos "fantasmas» ("a fantasia dicitur fantasma»), e constitui a matéria dos sonhos, das profecias e dos encantamentos da literatura.

Estes rápidos acenos podem dar a ideia de como, no século de Camóes, praticar a arte da memória ${ }^{1}$ chame em causa corpo e alma (e terra e céu, nos casos em que é

${ }^{1}$ Cfr. sobre o assunto P. Rossi, Clavis universalis. Arti della memoria e logica combinatoria da Lullo a Leibniz, Ricciardi, Milano-Napoli, 1960; F. A. Yates, The Art of Memory, Routledge and Kegan Paul, 
mais forte a influência neoplatónica): mesmo porque construir técnicas e imagens literárias significa reproduzir artificialmente alguns mecanismos primários da experiência humana para melhor observá-los e estudá-los. Se a fantasia e a imaginação se tornam ponto de contacto entre o homem e a realidade, entre particular e universal, a literatura e as práticas da memória reflectem ambiguidades e tensóes presentes, desde uma longa tradição, não só entre corpo e alma, mas sobretudo entre mente e coração, isto é, na complexa alquimia que regula a dinâmica entre razão e emoção.

Por tudo isso, um estudo verdadeiramente aprofundado e ainda por fazer das esparsas redondilhas camonianas significa antes de tudo voltar a percorrer aqueles territórios, ainda em grande parte inexplorados, em que as técnicas da memória interagem com experiências diversas: a tradução de palavras em imagens e de imagens em palavras, a experimentação sobre o imaginário, a percepção de si e do mundo própria de toda uma época.

As mnemotécnicas greco-latinas se apresentam em primeira instância, no panorama renascentista, como sequência de critérios empíricos fundados sobre associaçóes inspiradas em modelos retóricos que se apoiam, como indica Aristóteles (De memoria et reminiscentia, 451b, 18-20), em algo de símile, ou de contrário, ou de estreitamente relacionado. Assim como pode ser observado no comportamento natural, estes critérios utilizam três elementos essenciais: os lugares (loci), a ordem (ordo), as imagens (imagines agentes). Estas últimas, colocadas em posições devidamente ordenadas, estarão directamente relacionadas, através do jogo das associaçóes, com as res memorandae. A retórica, por sua vez, ou pelo menos aquela parte dela que é constituída pela elocutio, permite qualquer tipo de substituição, seja por semelhança que por contraste, da parte pelo todo ou da causa pelo efeito e vice-versa; e até por contrariedade ou oposição, como o pouco pelo muito na litotes, o muito pelo pouco na hipérbole e o direito pelo avesso na ironia. Desta maneira os textos se abrem a inúmeras sugestóes e as suas imagens se multiplicam reflectindo-se em espelhos diversos: o jogo da interpretação e da imitação/emulação os transforma em fontes de infinita riqueza. Jacques Gohory (1520-1576), literato francês profundo conhecedor da cultura italiana, tradutor de Maquiavel, amigo dos poetas da Pléiade, sequaz de Paracelso, fundador de uma academia onde se cultivava a botânica, a música e a alquimia, falou de textos/cornucópia referindo-se em particular ao "Teatro da memória» de Giulio Camillo: «Miro ordine condebat velut copiae quoddam cornu quod promere promptum esset ad de quacumque re proposita ornate copioseque dicendum» ${ }^{2}$. Deve-se observar que recentemente Terence

London, 1966; L. Bolzoni, "Il teatro della memoria”, Studi su Giulio Camillo, Liviana, Padova, 1984; M. Carruthers, "The Book of Memory", A Study of Memory in Medieval Culture, Cambridge University Press, Cambridge, 1990; L. Bolzoni e P. Corsi (org.), La cultura della memoria, Il Mulino, Bologna, 1992; J. J. Berns e W. Neuber (org.), Ars memorativa. Zur Kulturgeschichtlichen Bedeutung der Gedächtniskunt 14001750, Max Niemeyer, Tübingen, 1993; L. Bolzoni, La stanza della memoria, Einaudi, Torino, 1995.

${ }^{2} \mathrm{~J}$. Gohory, De usu et mysteriis notarum liber in quo vetusta literarum et numerorum ac divinorum ex Sibilla nominum ratio explicatur, Sertenas, Paris, 1550, c.C3v. No que respeita Giulio Camillo, uma ed. moderna da obra, publicada póstuma em 1550, que descreve o "Teatro da memória” foi realizada por L. Bolzoni, L'idea del theatro, Sellerio, Palermo, 1991. Sobre o assunto cfr. também L. Bolzoni, "Il teatro della memoria”, Studi su Giulio Camillo, Liviana, Padova, 1984 e Id., "La stanza della memoria”, cit. 
Cave $^{3}$ usou a mesma metáfora para descrever os mecanismos renascentistas da leitura e da imitação derivados da obra de Rabelais.

Se é verdade, portanto, que a ideia de uma mnemotécnica como semiótica, ou seja, como construção cujas estruturas reflictam as estruturas da realidade, afirma-se completamente só com Giordano Bruno e com os sequazes da pansofia barroca, é verdade também que no período quinhentista as tentativas de Giulio Camillo fazem parte de um contexto de grande fervor criativo: da Logica memorativa de Thomas Murner (Strasbourg, 1507) à Ars memorativa de Guglielmus Leporeus (Paris, 1520), do Congestorium artificiosae memoriae de Iohannes Romberch (Venezia, 1553) ao Thesaurus artificiosae memoriae de Cosma Rosselli (Venezia, 1579), até chegar àquela Ars reminescendi de Giovan Battista Della Porta (Napoli, 1602) que se situa no começo do século seguinte. É o período, em conclusão, em que a arte da memória conhece o seu momento de grande esplendor, tornando-se parte de um complexo movimento cultural que mira a uma refundação da enciclopédia e à conquista de uma chave universal de acesso ao saber.

2 - Neste quadro de fundo, as redondilhas camonianas, expressóes daquela «medida velha" que vai da lírica tradicional dos cancioneiros medievais aos poetas espanhóis senhores da redondilha (de Carvajal, Francisco Bocanegra e Santillana a Rodrigo de Reinosa e Juan del Encina), apresentam-se ao mesmo tempo como refinados jogos de sociedade e como produto de um gênero poético menor, no qual se reflecte tanto o ideal cavaleiresco e cortês da época quanto um ponto de vista realístico que traduz uma sensibilidade nova. Os motes ${ }^{4}$, sobretudo, fundam-se num esquema, ao mesmo tempo conceitual e rítmico, através do qual as técnicas da memória realizam um sistema móvel de ecos e paralelismos que produzem uma espécie de poesia/cornucópia, para usar a sugestiva metáfora de Gohory. Se, por um lado, este tipo de estrutura poética universaliza o conteúdo num número em teoria ilimitado de situaçóes, por outro, institui para os seus destinatários um código tradicional, virtual mas incontestável, que constitui um plano de referência insubstituível. Citação literal ou imitação paródica, locução estereotipada ou dito popular, este modelo de poesia epigramática tem a característica de repetir-se com infinitas variaçôes através da máquina retórica, segundo os ritmos de uma performance sempre diversa e sempre igual a si mesma. Com relação à fonte, verdadeira ou fictícia, a funçáo do poeta é de glosar a letra, de actualizar o modelo, muitas vezes segundo os procedimentos próprios da arte da memória. O elemento figurativo (imago agens) reenvia sempre a um comparante metafórico, a um fragmento de experiência extratextual (locus) e ao mesmo tempo a escolhas lexicais e sobretudo a esquemas sintáticos-rítmicos já prefigurados (ordo). Assim, por exemplo, um jardim florido é comparado com o rosto da dama para lembrar a força do amor em "Verdes são as hortas" ${ }^{5}$, ou o perigo dos olhos

3 Cfr. T. Cave, "The Cornucopian Text", Problems of Writing in the French Renaissance, Clarendon Press, Oxford, 1979.

4 Sobre o assunto, cfr. S. Peloso, «Un circuito poetico alternativo: i motes 'popolari' di Luís de Camões», in Quaderni Portoghesi, n. 6, 1979, pp. 31-56.

${ }^{5}$ Os textos são indicados com o primeiro verso segundo a edição de M. de Lurdes Saraiva (L. de Camóes, Lírica completa, prefácio e notas de M. de Lurdes Saraiva, vol. I, Imprensa Nacional, Lisboa, 1980). Salvo diversa indicação, a referência será sempre a esta edição. 
verdes em "Sois fermosa e tudo tendes"; a serra florida remete aos olhos iluminados de amor em "Se Helena apartar" e a erva do pasto às "graças dos olhos / do meu coração" em "Verdes são os campos"; o peso do trabalho no campo alude às penas de quem "semeava amor / e colhia enganos" em "Quem ora soubesse", assim como a imagem do caçador desesperado serve para introduzir os sofrimentos de quem fica preso nos laços de Amor em "No monte de Amor andei".

Poderíamos evidentemente continuar, mas o que importa sobretudo sublinhar em todos estes exemplos é a estreita relação, não só nas Redondilhas mas em geral na lírica camoniana, entre imagem e palavra, entre poesia e elemento figurativo, em função da recuperação, através do teatro da memória, de toda uma tradição. Inspirada no cânone do ut pictura poesis, a reflexão teórica quinhentista valoriza um património de memória que envolve palavras e imagens, enriquecendo e variando, através do jogo hermenêutico, os respectivos «depósitos» tópicos (loci mentais paragonados às prateleiras de uma biblioteca na Plutosofia, Padova, 1592, do franciscano Filippo Gesualdo). O próprio Pietro Bembo, aquele mesmo Bembo que Duriano, no "Auto de Filodemo", mandará ao diabo junto com Petrarca e "atoado a trezentos Platóes» ${ }^{6}$, nos Asolani (Venezia, 1505), tratando de como os poetas tentam dar forma ao domínio do multíplice através de instrumentos tópicos, explica que eles às vezes falam de sentimentos que não provam «ma fannolo per porgere diversi suggetti agl'inchiostri, acciò che con questi colori i loro fingimenti variando, l'amorosa pintura riesca a gl'occhi de riguardanti più vaga» ${ }^{7}$. A estreita relação entre pintura, poesia e memória se reflecte também no mito do fundador da arte da memória: aquele Simónides de Ceos, poeta da idade pré-socrática, o primeiro, segundo Plutarco (De gloria Athenensium, II, 346f-347c), a afirmar que a pintura é poesia muda e a poesia pintura falada ${ }^{8}$. Camóes também o recorda na sua célebre elegia:

"O poeta Simónides, falando

Co’o capitão Temístocles, um dia

Em cousas de ciência praticando,

$\mathrm{Ua}$ arte singular lhe prometia,

Que entáo compunha, com que lhe ensinasse

A se lembrar de tudo o que fazia;

Onde tão sutis regras lhe mostrasse

Que nunca lhe passassem da memória

Em nenhum tempo as cousas que passasse.

Bem merecia, certo, fama e glória

Quem dava regra contra o esquecimento

Que enterra em si qualquer antiga história.

Mas o capitáo claro, cujo intento

Bem diferente estava, porque havia

${ }^{6}$ L. de Camões, "Auto de Filodemo", in Obras Completas, com prefácio e notas de H. Cidade, vol. III, Sá da Costa, Lisboa, 1946, p. 154.

7 P. Bembo, Asolani, ed. crítica de G.Dilemmi, Accademia della Crusca, Firenze, 1991, p. 270.

${ }^{8}$ Cfr. G. Lanata (org.), Poetica pre-platonica, La Nuova Italia, Firenze, 1963, pp. 68-71. 
As passadas lembranças por tormento,

- Ó ilustre Simónides! - dezia -

Pois tanto em teu engenho te confias

Que mostras à memória nova via,

Se me desse ua arte que em meus dias

Me não lembrasse nada do passado,

Oh! quanto milhor obra me farias!"9

Inútil sublinhar a importância destes versos para uma poética inspirada, como já vimos, nas «sutis regras contra o esquecimento»; vale a pena, no entanto, destacar que temos aqui um outro reflexo preciso da teoria quinhentista também na declarada vontade de esquecer de Temístocles. Uma rica tradição filosófica e médica, de origem clássica, considera, com efeito, as imagens através das quais nós pensamos e lembramos como «fantasmas» que agem na interioridade e podem escapar ao nosso controle. Como um sigilo na cera, diz Aristóteles, no De memoria et reminiescentia (I, 450a, 30), que as imagens e as sensaçóes produzem na nossa interioridade uma espécie de desenho, que existe contemporaneamente em função da memória e da virtus imaginativa. Construir o teatro da memória, portanto, significará exaltar todas as potencialidades da imaginatio, mas também recriar o mundo com uma operação alquímica em que as diversas metamorfoses tomam forma, tornando-se imagens, fantasmas e simulacros. Temos um eco muito claro desta teoria na redondilha camoniana "Vejo-a n'alma pintada”, cuja glosa alude também à perda da alma e da identidade:

"Se só no ver puramente
me transformei no que vi,
de vista tão excelente
mal poderei ser ausente
enquanto o não for de mi.
Porque a alma namorada
a traz táo bem debuxada,
e a memória tanto voa
que, se a não vejo em pessoa,
vejo-a n'alma pintada."

(vv. 4-13, p. 174)

Não diverso, na citada elegia, o significado dos vv. 9-14, que aludem claramente ao mesmo processo:

"De que serve às pessoas alembrar-se

Do que se passou já, pois tudo passa,

Senão de entristecer-se e magoar-se?

Se noutro corpo ua alma se traspassa,

${ }^{9}$ L. de Camóes, Obras completas, com prefácio e notas de H. Cidade, vol. II, Sá da Costa, Lisboa, 1968 (1ª ed. 1946), p. 199. 
Não como quis Pitágoras, na morte,

Mas como manda Amor, na vida escassa [...]"

Giulio Camillo no "Discorso in materia del suo theatro" (1532), citando Avicena, afirma "nell'anima nostra essere una certa virtù di alterare le cose, et farle obedienti a noi, mentre l'anima nostra è portata da alcuna grande affetion sopra esse. Et di qui credono alcun esser nate le incantagioni et le negromantie» ${ }^{10}$. Segundo Avicena (De Anima, 4), com efeito, quando a alma se fixa numa imaginação, a matéria corpórea também pode receber uma forma que é ligada àquela imaginada através de uma qualidade ou similitude qualquer. A relação entre as capacidades mágicas da virtus imaginativa e a arte da memória, evocada por Giulio Camillo, funda-se portanto na possibilidade das imagines agentes imprimirem-se na nossa alma com êxito imprevisto. Nas Redondilhas de Camóes temos inúmeros exemplos deste topos da tradição clássica e medieval:

"Eu para levar a palma com que ser vosso mereça, quero que o corpo padeça por vós, que dele sois alma. Vós do corpo vos queixais, eu queixar-me de vós posso; porque, tendo um corpo vosso, na minh'alma vos sangrais.” (“Com razão queixar-me posso", vv. 5-12, p. 63)

"Não vos guardei, quando vinha, em torre, força ou engenho; que mais guardada vos tenho em vós, que sois alma minha. Ali, nem frio nem calma não podem ter jurdição; na vida sim, porém não em vós, que tenho por alma." ("Ferro, fogo, frio e calma", vv. 5-12, p. 139)

"Se me for e vos deixar (ponho, por caso, que possa), esta alma minha, que é vossa, convosco me há-de ficar.

Assi que só por levar a minh'alma, se me for, vos levarei, meu amor."

("Se me desta terra for", vv. 3-9, p. 189)

${ }^{10}$ G. Camillo, "Discorso in materia del suo theatre", in Opere, Domenico Farri, Venezia, 1579, p. 11. 
"Amor, cuja providência

foi sempre que não errasse

por que n'alma vos levasse,

respeitando o mal de ausência,

quis que em vós me transformasse.

E vendo-me ir maltratado,

eu e meu cuidado sós,

proveio nisso, de atentado,

por não me ausentar de vós,

sem vós e com meu cuidado."

(“Sem vós e com meu cuidado", vv. 3-12, p. 196)

Em 1582, no Discorso intorno alle imagini sacre e profane, o cardeal Gabriele Paleotti chama a atenção para o perigo criado pela força da "imaginatio", porque sendo "la imaginativa nostra cosi atta a ricevere tali impressioni, non è dubbio non ci esser istrumento più forte o più efficace a ciò delle immagini fatte al vivo, che quasi violentano i nostri sensi incauti» ${ }^{11}$. Não há duvida, nesta situação, que o único remédio pode consistir na elaboração de uma "ars oblivionis", capaz de corrigir os excessos da "ars reminiscendi”, de que temos vários testemunhos no séculos XV e XVI. Giovanni Fontana, por exemplo, no Secretum de thesauro experimentorum ymaginationis hominum (1430) elenca vários métodos para eliminar as imagens da memória ou pelo menos atenuar a sua força vital, assim como mais tarde o florentino Cosma Rosselli no já citado Thesaurus artificiosae memoriae (1579), o franciscano vêneto Filippo Gesualdo em "L'arte de scordarse", capítulo final da sua Plutosofia (1592) e o belga Lambert Schenkel (1547-1603) no De memoria liber (1595), depois publicado novamente em 1610 com o título Gazophilacium artis memoriae ${ }^{12}$. A disputa entre Simónides e Temístocles na já referida elegia camoniana se enquadra, portanto, numa problemática tipicamente quinhentista, que tem a ver com a relação entre alma, imagens e jogo da memória. Um outro topos, despercebido à maioria dos comentadores, que encontramos na redondilha "Pus meus olhos nũa funda", refere-se ao mesmo tema:
"Mote seu
Pus meus olhos nua funda
e fiz um tiro com ela
às grades de ua janela.
Voltas
Ua dama, de malvada,
tomou seus olhos na mão

\footnotetext{
${ }^{11}$ G. Paleotti, Discorso intorno alle immagini sacre e profane, Alessandro Benacci, Bologna 1582, p. 230.

${ }^{12}$ Cfr. a ed. do "Secretum de thesauro experimentorum ymaginationis hominum" in E. Battisti e G. Saccaro Battisti, Le macchine cifrate di Giovanni Fontana, Arcadia, Milano, 1984, pp. 143-158; C. Rosselli, Thesaurus artificialis memoriae, Antonio Padovano, Venezia, 1579, c. 129v; F. Gesualdo, Plutosofia, Paolo Megietti, Padova, 1592, c. 64r; L. Shenkel, Gazophylacium artis memoriae, Antonius Bertramus, Strasbourg, 1610, p. 124. Sobre o assunto cfr. L. Bolzoni e P. Corsi (org.), La cultura della memoria, Cit. e L. Bolzoni, La stanza della memoria, cit.
} 
e tirou-me ua pedrada

com eles no coração.

Armei minha funda então,

e pus os meus olhos nela;

Trape! quebro-lh'a janela."

(vv 1-10, p. 232)

Aqui o verdadeiro sentido do texto só pode ser colhido no jogo de significados estabelecido entre a janela real e aquela «janela do coração» que, de Esopo até Sócrates, este último recuperado com base no prefácio ao terceiro livro do De Architectura de Vitruvio, funda-se numa longa tradição que chega até aos tratadistas do século XVI. Giulio Camillo, por exemplo, no Pro suo de eloquentia theatro ad Gallos oratio (1587) alude à mesma tradição, quando afirma: "Nostra haec manufacta mens, nostra haec tanti operis fabrica, ita fenestrata est, ut apertiorem non potuisset desiderari a Socrate» ${ }^{13}$. No que respeita à interpretação do topos, sobretudo na sua versão quinhentista, Mario Andrea Rigoni ${ }^{14}$ o considera como exemplo de uma vocaçáo profunda e de um inalcançável telos da tradiçáo ocidental: abolir a separação entre interioridade e exterioridade e revelar o próprio mundo como domínio da máscara. Sem esquecer, acrescenta por sua vez Lina Bolzoni, que "a imagem da janela aberta sobre o coração reuniu em si exigências e mitos diversos: a absoluta transparência do ser, de que ela exprime emblematicamente a fraqueza e as contradiçóes, mas também a ideia que seja possivel tornar visivel o modo em que a ideia toma forma quando se deposita na imaginação, a maneira em que a linguagem reveste os conceitos, dando a eles consistência» ${ }^{15}$. Quanto a Camóes, o motivo revive, na redondilha citada, numa versão satírico-humorística em que, como sempre neste poeta, a tradição neoplatónica convive e se contamina com outras tradiçôes e experiências.

3 - Outros textos nas Redondilhas são mais directamente relacionados com as regras de mnemotécnica referidas nos tratados quinhentistas e herdadas da tradição clássica grega e romana. Já num fragmento de época pré-socrática, estudado por Hermann Diels $^{16}$, são citados, por exemplo, dois procedimentos para lembrar um conceito abstracto ou uma personagem: o primeiro consiste num repertório estandardizado de imagens para recordar feitos e situaçóes particulares (por exemplo a associação de uma prática ou de uma virtude à divindade ou ao herói que a representa); o segundo, com o mesmo objectivo, recorre à decomposição de palavras e nomes próprios em ideogramas que representam parte deles, como nos rébus. É claro que o primeiro procedimento levará através dos séculos à constituição de repertórios iconológicos depois utilizados

13 A citação se encontra na p. 39 do texto impresso em Venezia, em 1587, por Giovan Battista Somaschi. Sobre o assunto cfr. C. Bologna, Esercizi di memoria. Dal «Theatro della sapientia» di Giulio Camillo agli «Esercizi spirituali» di Ignazio di Loyola, in L. Bolzoni e P. Corsi, La cultura della memoria, cit., pp. 169-221.

14 M. A. Rigoni, «Una finestra aperta sul cuore. (Note sulla metafora della 'Sinceritas' nella tradizione occidentale)", in Lettere Italiane, IV, 1974, pp. 434-458.

15 L. Bolzoni, La stanza della memoria, cit., pp. 154-164 [a pp. 160-161]. A tradução é minha.

16 H. Diels, Die Fragmente der Vorsokratiker, II, Weidmann, Berlin, 1922, p. 345. 
nos tratados da segunda metade do séc. XV e do séc. XVI. Camões utiliza este expediente mnemotécnico na composição "Ana quisestes que fosse", um verdadeiro abecedário mitológico em tercetos em que os vários personagens representam os loci, ponto de referência para a construçáo de imagines agentes, de vícios e virtudes relacionadas com a paixão amorosa do poeta, segundo a ordem constituída pelo alfabeto:

"MM

Minerva dizem que foi, e Palas, deusas da guerra: e vós, Senhora, da terra. Medeia foi mui cruel, mas não chegou a metade de vossa grão crueldade."

$$
\text { (vv.67-72, p. 179) }
$$

O segundo procedimento, que dará vida a uma tradição não menos ampla e articulada, em que se realizará, entre caligrafia, cifra e rébus, a fantasmagoria de uma escrita que prelude à época barroca, é exemplificado em Camóes nas trovas "Se derivais de verdade":

\footnotetext{
"Se derivais de verdade esta palavra Sitim, achareis, sem falsidade, que após o si, tem o tim, que tine em toda a cidade.

Bem vejo que me entendeis; mas, por que não fale em vão, sabei que a esta nação tanto que o si concedeis o tim logo está na mão.” (vv. 1-10, p. 147)
}

ou no mote:

"Vejo-a n'alma pintada, quando ma pede o desejo, a natural que não vejo.”

$$
\text { (p. 175) }
$$

que esconderia, come se pode ver, o nome Joana.

É claro que aqui o antigo expediente mnemotécnico se torna função daquela linguagem cifrada, que se exprime nos mitos, na poesia dos clássicos, nos textos dos alquimistas. No século de Camóes esta espécie de paixão pelo espaço escuro que se abre entre significante e significado atravessa todas as camadas sociais, da praça ao palácio, exprimindo-se numa grande variedade de artifícios. Nas Redondilhas temos também o caso das "estâncias na medida antiga" "Sois ua dama", em que a técnica 
poética consiste em construir versos com uma leitura vertical e outra horizontal e dois códigos antonímicos e complementares. Desta maneira, observa Luciana Stegagno Picchio, "o Camóes da 'medida velha' constrói para si, na sombra do vate nacional, um pequeno mito de inventor de criptogramas e de desenvolto homem mundano. E jogando sobre a montagem e a sucessão dos segmentos, isto é, sobre a cadeia sintagmática mais do que sobre as associaçôes paradigmáticas próprias do estilo engenhoso, cria o seu enigma» ${ }^{17}$. Um exemplo não muito diferente é constituído pelo "labirinto" "Corre sem vela e sem leme", que, como se sabe, pode ser lido indiferentemente do princípio para o fim ou vice-versa, com a possibilidade também de outras leituras emparelhadas, agrupando de maneira diferente versos e estrofes. Nestes e noutros casos temos a demonstração de que o entrelaçamento entre linguagem cifrada, ars combinatoria, rebus e técnicas da memória se, por um lado, contribui para uma experimentaçáo literária e filosófica, alargando os confins da linguagem e misturando os códigos expressivos, por outro, numa cultura como aquela quinhentista em que é muito forte a tendência ao sincretismo, acaba por dar espaço às teorias neoplatónicas e herméticas sobre a "sabedoria encoberta», ocultada nos mitos e na poesia.

4 - Neste sentido as redondilhas "Sobre os rios que vão" aparecem como indicativas de todo um percurso, não só no interior da lírica camoniana, mas na cultura quinhentista em geral, cuja meta não será fácil de alcançar. Em termos de organização e de estrutura do texto deparamos com o mesmo esquema: em lugar dos motes temos os versículos do salmo 136 "Super flumina Babylonis", em que as res memorandae são passos bíblicos, assim como na Ars memorandi (Pforzheim, 1502) tratava-se de passos do evangelho. Só que desta vez o cenário mudou completamente e o platonismo, absorvido através do neoplatonismo ficiniano e talvez com a mediação do Breviarium do pseudo Jerónimo, leva Camóes àquela doutrina da reminiscência condenada em todos os Concílios:
"Mas ó tu, terra de Glória, se eu nunca vi tua essência, como me lembras na ausência?
Não me lembras na memória, senão na reminiscência.
Que a alma é tábua rasa que, com a escrita doutrina celeste, tanto imagina que voa da própria casa, e sobe à pátria divina."

Vasco Graça Moura, num trabalho de 1984 recentemente reproposto ${ }^{18}$, fala de esquemas pitagóricos-matemáticos aplicados ao texto, sobretudo a teoria do número

${ }^{17}$ L. Stegagno Picchio, "Ars combinatoria e algebra delle proposizioni in una lirica di Camôes", in Studi Romanzi, XXXV, 1973, pp. 7-39 [a pp. 14-15]. A tradução é minha.

${ }^{18}$ Cfr. V. Graça Moura, Camóes e a divina proporção, Imprensa Nacional, Lisboa, 1994. 
de ouro, que é tomada como modelo de uma sabedoria em condiçôes de atingir a Unidade através de uma série de relaçóes proporcionais, assim como sugere o De divina proportione (1509) de Luca Pacioli. Lembramos que o próprio Luca Pacioli e Sigismondo Fanti, astrólogo e matemático de Ferrara contemporâneo de Ariosto, eram na época, os principais intérpretes de uma linha que visava aplicar aos modelos gráficos as mesmas proporçóes que Vitrúvio tinha proposto para a arquitectura. Mais tarde, em 1573, Silvio Belli, matemático e arquitecto amigo do Palladio, publicará uma outra obra intitulada Della proportione et proportionalità communi passioni del quanto, em que, assim como no Triompho di Fortuna (1527) do Fanti, tenta-se encontrar, através da "geometrica ragione», a "vera e abdita proportione», que está na base da estrutura da natureza e do mundo ${ }^{19}$.

A busca de uma clavis universalis para resumir e interpretar a realidade é, portanto, o grande sonho da arte da memória, mas também do saber hermético com ela estreitamente relacionado no período renascentista. E aqui reside a insanável contradicção, de que, em termos artísticos e culturais, encontramos uma grande ressonância também na obra de Camóes. O fim da ars reminiscendi deveria ser aquele de reduzir a uma ars combinatoria muito económica e a uma regra de correlação elementar seja o universo dos artifícios expressivos que o universo das res memorandae; mas para fazer isso ela tem que recorrer àquelas signaturae rerum (ou seja àqueles aspectos formais das coisas que reenviam por semelhança aos aspectos formais de outras coisas) que estão na base da sabedoria hermética. Abre-se assim um jogo de correspondências proteiforme e sem fim que acaba por tornar inutilizáveis os vários «teatros da memória». Como escreve Michel Foucault, "a semelhança não demora nunca estável em si mesma: permanece fixada somente se reenvia a uma outra similitude, que por sua vez solicita outras; de maneira que cada semelhança tem valor só em virtude da acumulaçáo de todas as outras, e o mundo inteiro tem que ser percorrido para que a mais ténue das analogias seja justificada e apareça, afinal, como certa... O saber do século XVI se condenou a conhecer nada mais que o idêntico, mas a conhecê-lo só ao cabo, nunca alcançado, de um percurso sem fim». ${ }^{20}$

${ }^{19}$ S. Fanti, Triompho di fortuna, Agostino Portese, Venezia, 1527; S. Belli, Della proportione et proportionalità communi passioni del quanto, Francesco Patrizi, Venezia, 1573.

${ }^{20}$ M. Foucault, Les mots et les choses, 1966. Cito da trad. italiana Le parole e le cose, Milano, Rizzoli, 1967, pp. 44-45. A versão portuguesa é minha. Sobre o assunto cfr. também U. Eco, «Bruno: combinatoria e mondi infiniti», in Id. La ricerca della lingua perfetta, Laterza, Bari, 1993, pp. 145-155. 